\title{
O Drama da Imanência: Gebhardt, Deleuze, Benjamin e o Infinito Barroco de Espinosa
}

[The Drama of Immanence: Gebhardt, Deleuze, Benjamin and Spinoza's Baroque Infinite]

\section{Henrique Piccinato Xavier ${ }^{\Uparrow}$}

Resumo: Investigando a filosofia de Espinosa, visamos atravessar o drama da imanência elaborado por Walter Benjamin em Origem do drama barroco alemão, isto é, atravessar a peculiar interpretação melancólica que relaciona a ideia de imanência presente na filosofia moderna à arte de sua época, ou seja, a barroca. Mais que um drama, para um olhar espinosano, tal interpretação é uma tragédia, pois produz uma teatralidade aporética que dilapida a positividade da ideia de imanência. Para compreendermos esta tragédia, será preciso passar por dois preâmbulos filosóficos ao drama: Rembrandt e Espinosa de Carl Gebhardt e A dobra: Leibniz e o barroco de Gilles Deleuze. Da melancólica tragédia para algo mais feliz, reelaboraremos o drama, procurando desfazer tais aporias, conduzindo-nos à compreensão da positividade da imanência "barroca" em Espinosa.

Palavras-chave: Espinosa, Carl Gebhardt, Gilles Deleuze, Walter Benjamin, Arte Barroca.

Abstract: With Espinosa's philosophy, we aim to confront the drama of immanence developed by Walter Benjamin in his The Origin of the German Tragic Drama, in other words, we aim to confront a peculiar melancholic interpretation that relates the idea of immanence present in modern philosophy to the art of its time, that is, baroque art. More than a drama, in a Spinosist perspective, such interpretation is a tragedy, because it produces an aporetic theatricality that demolishes the positivity in the idea of immanence. To understand this tragedy, it will be necessary to go through two philosophical preambles to this drama: Rembrandt and Spinoza by Carl Gebhardt and Fold: Leibniz and the Baroque by Gilles Deleuze. We will rework the drama from the melancholic tragedy to something happier, trying to undo these aporias, leading us to an understanding of the positivity of the "baroque" immanence in Spinoza.

Keywords: Spinoza, Carl Gebhardt, Gilles Deleuze, Walter Benjamin, Baroque Art.

${ }^{*}$ Doutor em Filosofia pela Universidade de São Paulo (USP). E-mail: henrique.xavier0@gmail.com. ORCID:https://orcid.org/0000-0001-7325-0252 


\section{I - Preâmbulos ao drama}

O absolutamente infinito, ou seja, a substância (ou a natureza) na filosofia de Espinosa é ordenada segundo leis eternas, universais e imutáveis, como nos afirma a cada passo da Parte I da Ética. Mas o que, de fato, são estas leis eternas senão a pura movimentação da transformação de auto-diferenciação infinita de si mesmo, uma atividade infinita de uma essência atuosa? Lembremos da Proposição 16 da parte I da Ética: "Da necessidade da natureza divina devem seguir infinitas coisas em infinitos modos (isto é, tudo que pode cair sob o intelecto infinito)" (ESPINOSA, 2015, p. 75). Assim, a substância produz infinitas coisas sob infinitos atributos, seus modos infinitos e modificações finitas. Ademais, sabemos que esta essência atuosa não age segundo um fim, mas flui absolutamente livre, pois a essência atuosa da substância concebida como causa sui radica na sua completa liberdade, afinal, a substância é a causa de si, ou seja, sua existência exprime a si mesma e que, por sua vez, não é limitada por nada e nem por si mesma, sendo ela mesma a abertura de uma transformação infinita sem teleologia e sem finalismo. De fato, pela relação de imanência da substância infinita até suas modi- ficações finitas, na natureza não há nenhum evento excepcional para além de suas leis eternas, por isso, nela não pode haver o milagre como evento que se sairia da ordem da natureza, pois neste caso a natureza deixaria de ser a natureza. Exatamente por sua essência atuosa radicar na mais completa liberdade, em Espinosa, há uma natureza absolutamente infinita que em sua imanência é necessariamente e por completo sempre renovada, ou seja, temos uma natureza que apenas produz coisas, ideias e essências singulares.

Se a passagem do infinito ao finito é deduzida, como afirmarmos, a partir da Proposição 16 da Parte I da Ética, a operação inversa, ou seja, a passagem entre o finito (modos finitos) e o infinito (a substância única) será realizada pela síntese dinâmica como lei de interação entre partes, que não segue uma finalidade preestabelecida ou um modelo exterior, mas constitui um infinito de relações que produz a si mesmo em uma ordenação imanente: este e um dos pontos centrais da filosofia de Espinosa. Contudo, ela nos coloca diante do seguinte problema: como agir individualmente, no interior da finitude, sendo parte de um fluxo dinâmico e absolutamente infinito? Como, desde seu interior, não apenas ser uma parte, 
mas ao se-la, também, já tomar parte ativa neste infinito? Cremos que o grande problema reside na dificuldade para entender a positividade de um sistema aberto, ainda mais quando este e absolutamente infinito.

Heinrich Wölfflin, em Renascença e barroco ${ }^{1}(1888)$ e em Conceitos fundamentais da história da $\operatorname{arte}^{2}$ (1915), textos fundantes dos estudos contemporâneos acerca da pintura clássica e barroca, mostra-nos como o estilo barroco produz a liberação das formas de seu isolamento, o princípio da representação barroca sendo a substituição da composição de formas fechadas da arte clássica por um movimento visual em direção a uma unidade entre parte e todo, que, em uma visualidade fluida, dissolve a anterior estrutura rígida dos contornos das figuras do estilo clássico. Wölfflin afirma o entendimento da experiência da pintura do XVII como um ordenamento que se transforma diante dos olhos do observador.

Se consideramos a passagem entre finito e infinito um dos grandes desafios que a filosofia de Espinosa enfrenta, como emendar (ou seja, curar) um melancólico problema matemático, epistemológico e ontológico, produzindo a continuidade na passagem entre nós, seres limitados (ou seja, modos finitos da substância infinita) e o absolutamente infinito indivisível (ou seja, a substância única)? A emenda da incomensurabilidade numérica e imaginária do infinito irá garantir ao entendimento a condução a uma nova síntese intelectual de um infinito positivo, este não mais definido em termos negativos, indefinidos ou potenciais (que se contentam em delinear a constância ou inconstância de relações truncadas na justaposição de partes), mas, sim, como um absolutamente infinito real, em ato, positivo e indivisível.

Ao abordarmos, portanto, a passagem entre finito e infinito ${ }^{3}$ na filosofia de Espinosa e as afirmações de Wölfflin acerca do barroco, surge-nos a pergunta: como conceber ordem em uma natureza que mescla a parte e o todo, e preservar uma identificação sem que esta se torne uma identidade estanque, tanto na filosofia que expressa o absolutamente infinito da

\footnotetext{
1 WOLFFLIN, H. (2005) Renascença e barroco. São Paulo, Perspectiva.

2 WOLFFliN, H. (1984) Conceitos fundamentais da História da Arte. São Paulo, Martins Fontes, 1984.

${ }^{3} \mathrm{O}$ presente artigo faz parte de um conjunto maior de trabalho e pesquisa. Assim, as questões aqui propostas podem ser lidas em continuidade às questões trabalhadas no artigo 'Espinosa, melancolia e o absolutamente infinito na geometria dos indivisíveis do século XVII' (XAVIER, 2016) que tematiza a passagem entre finito e infinito na filosofia de Espinosa.
} 
substância, como no rompimento da forma pela visualidade infinitamente aberta do barroco? Cremos que esta questão constitui um dos problemas centrais de uma aproximação crítica da filosofia de Espinosa à arte de sua época. Para respondê-la, iremos nos contrapor a uma das mais célebres e históricas interpretações da relação entre arte barroca e filosofia da imanência: o drama da imanência cunhado por Walter Benjamin. Veremos que, em uma perspectiva espinosana, para além de um mero drama, tal interpretação será uma melancólica tragédia, produzindo uma teatralidade aporética que dilapida toda e qualquer positividade para a ideia de imanência. Para darmos conta deste drama, precisaremos antes passar brevemente por dois preâmbulos, duas interpretações contemporâneas, uma de Gebhardt, outra de Deleuze, que relacionam a filosofia do século XVII à arte seiscentista.

\section{Preâmbulo I - Gebhardt, Rem- brandt e Espinosa, 1927}

Em seu clássico texto intitulado Rembrandt e Espinosa, Carl Gebhardt, em uma aproximação entre a obra do filósofo e a do pintor barroco, afirma que: barroco dá-lhes a inquietude de esboços privados de ordem, e não fecha o ponto de vista que devemos ter sobre eles, a fim de que a infinidade da obra disforme não seja restringida pela limitação de uma forma. (GEBHARDT, 2000, p.106)

Gebhardt entende a composição aberta barroca como algo privado de ordem, cujo efeito produziria uma obra que não seria restringida pela forma fechada. Prosseguindo, o autor extrapola tal ideia de matriz wölffliniana até chegar à radical conclusão de que "o Renascimento definiu a beleza como a conspiração das partes e a encontrou realizada na razão natural, contudo, a beleza do barroco, enquanto uma forma não limitada, é irracional" (GEBHARDT, 2000, p.107). Gebhardt conclui algo sobre o barroco que buscará aproximar de Espinosa, mas que contradiz a própria letra do filósofo. De fato, Gebhardt afirma que algo por não ser limitado seria irracional, quando em Espinosa verificamos claramente o contrário, pois, de um lado, a substância ou o absolutamente infinito é ilimitado (em contraposição ao limite que define o finito), mas é o mais inteligível ou o mais racional 
de todos os seres (como vemos demonstrado na Parte I da Ética), sua potência é livre porque determinada apenas por si mesma, sendo por isso causa de si que flui naturalmente por si mesma, desprovida de uma causa externa ou um limite externo. Por ser causa de si absolutamente infinita é inteligível, pois a inteligibilidade decorre do conhecimento da causalidade e de suas ações; ou seja, a ausência de limites convém perfeitamente com a razão. Contudo, cremos que Gebhardt associa a deformidade e o irracionalismo à filosofia de Espinosa, pois está influenciado pela leitura de tradição alemã, que vê em Espinosa uma operação de dissolução do singular no seio do absoluto, como fora almejada pelos românticos (Schelling, principalmente), e que, a partir de Hegel (inspirado em Bayle), toma a forma negativa de um acosmismo 4 . Considerando, na filosofia de Espinosa, o absoluto como indiferenciação e indeterminação absolutas, faltaria a essa filosofia um princípio de identidade para os modos finitos, existindo, então, realmente apenas a substância, desprovida de qualidades e de diferenças - portanto, indeterminada, donde, impensável ou irracional. Em outras palavras, o infinito é irracional e o finito, impensável. Gebhardt reproduz quase literalmente o texto hegeliano, alegando que em Espinosa "abertura ao infinito da substância acabaria com a possibilidade de existir identidades" e, ainda mais, ele redobra essa afirmação para o barroco de Rembrandt, cuja obra seria uma arte espinosista acosmista: "a categoria do barroco é a da substancialidade, segundo a qual tudo o que é particular possui apenas uma existência relativa, tanto que a existência verificável pertence apenas à totalidade infinita, eis o que custo a dizer (em relação às coisas particulares): que só existe a substância" (GEBHARDT, 2000, p.107).

\footnotetext{
4 É vasta e complexa a crítica que Hegel faz a Espinosa, contudo, gostaria de insistir que um de seus pontos altos é identificação da filosofia de Espinosa ao acosmismo. Segundo Hegel, na demonstração espinosana da unidade absoluta da substância o sujeito necessariamente se perderia, se diluiria, neste absoluto, excluindo a possibilidade do principio ocidental da individualidade. Em grande parte a própria dialética hegeliana e sua ontologia seriam a tentativa de superar este dilema. Nas Lições sobre a história da filosofia de 1825-26, Hegel escreve no parágrafo de abertura de seu artigo sobre Espinosa: "Esta profunda unidade de sua filosofia [de Espinosa], tal como ela foi expressa na Europa, - o espírito, o finito e o infinito idênticos em Deus, e não mais como um terceiro termo[...]" e, mais adiante no mesmo parágrafo, ele explicita o acosmismo de Espinosa: "o modo como tal [definido por Espinosa] é justamente o não-verdadeiro, e somente a substância é verdadeira". (HEGEL, 1970, Leçons sur l'histoire de la philosophie. Paris, Gallimard, verbete sobre Espinosa).
} 
Preâmbulo II - Deleuze, $A$ dobra: Leibniz e o barroco, 1988

Gilles Deleuze, na conclusão de $A$ Dobra: Leibniz e o Barroco, segue e amplia uma ideia central no livro de Gebhardt de que obra de arte barroca opera a interação ativa de uma continuidade entre o interno e o externo em um turbilhão de movimentos que parece não se delimitar por nada nem por si, sendo como um gesto que se expande para além de si mesmo em uma multiplicidade de relações simultâneas 5 :

O quadro é uma parte do infinito que transborda da moldura, a estátua é um turbilhão do rio infinito que uiva por através da igreja barroca, e o espaço mesmo da igreja se constitui num quadro de altar, e uma estátua não é nada outro que a nave do infinito (GEBHARDT, 2000, p.107).

Na versão desdobrada de Deleuze, em uma das passagens mais belas do livro:
Se o Barroco instaurou uma arte total ou uma unidade das artes, isso se deu primeiramente em extensão, tendendo cada arte a se prolongar e mesmo a se realizar na seguinte, que a transborda. Observou-se que o Barroco restringiria frequentemente a pintura e a circunscreveria ao retábulos, mas isso ocorreria porque a pintura sai da sua moldura e realiza-se na escultura em mármore policromado; e a escultura ultrapassa-se e realiza-se na arquitetura; e a arquitetura, a sua vez, encontra na fachada uma moldura, mas essa própria moldura desloca-se do interior e coloca-se em relação com a circunvizinhança, de modo que realiza a arquitetura no urbanismo (DELEUZE, 1991, p.187).

Ainda que o livro de Deleuze seja sobre Leibniz e o barroco, a força de tal ideia - que apresenta, nas

\footnotetext{
${ }^{5}$ Esta característica torna-se extremamente patente na produção artística seiscentista, por exemplo, no drama em que palco fictício era posto no próprio palco, ou quando o auditório era incluído na cena (BENJAMIN, W. Origem do drama barroco alemão. São Paulo, Brasiliense, 1984); nas pinturas que possuem molduras pintadas dentro da sua representação, ou quando as próprias molduras se tornam tão importantes quanto as obras de arte por elas cercadas; no uso de espelhos da que refletem espaços para além da própria superfície da tela, como nas Meninas de Velázquez; ou ainda, na inacreditável dinâmica dos movimentos em todas as direções nas esculturas de Bernini.
} 
obras de arte seiscentistas, uma causa atuosa que faz com que elas se expandam tanto internamente quanto externamente em um contínuo como uma multiplicidade de relações ativas - irá abalar a argumentação deleuziana acerca de Leibniz. Ora, a tal ideia não nos afastaria de Leibniz, pois a força desta poética que nos leva a interpretá-la como expressão da ideia de um infinito em ato ou absolutamente infinito, que nunca poderia ser a decorrência de uma predeterminação, mas se constitui exatamente como a própria ordem de interação e de transformação de uma realidade concebida em ato a partir de partes intra partes ${ }^{6}$. Não haveríamos nos aproximado de Espinosa? De fato, a ideia de uma ordenação como uma abertura para uma multiplicidade simultânea se aproxima muito da imanência em Espinosa. Assim, a despeito da intenção de uma leitura leibniziana do barroco, vemos Deleuze, em sua dobradura, necessariamente chegar a uma conclusão que o distancia de Leibniz. Neste sentido, o espinosismo, influência inegável nas obras de Deleuze, ainda que não seja mencionado explicitamente, faz sentir-se em sua presença maciça: não teríamos em sua conclusão um barroco espinosano? Eis que na conclusão de A dobra: Leibniz e o barroco, após uma longa aproximação sistemática entre a harmonia pré-estabelecida das mônadas e a harmonia da música barroca em acordos/acordes, mônadas tônicas/dominantes, Deleuze faz o inesperado e rompe a base mais elementar do pensamento de Leibniz: abre as mônadas. Estas, que necessariamente sempre estariam submetidas à clausura, em cujo interior se incluiria o universo inteiro (não podendo haver existência fora delas), ao serem abertas romperiam diretamente, tanto com a filosofia de Leibniz, quanto com a própria sistematização entre a harmonia musical e a harmonia metafísica que o autor acabara de propor. Segundo Deleuze, a seleção que as mônadas operam acabaria por desapa-

\footnotetext{
6 Tanto Espinosa como Leibniz operam com a ideia de absolutamente infinito ou infinito em ato, uma ideia que se contrapõe à noção de um infinito potencial e acumulativo, ou seja, composto pela adição de partes discretas. $\mathrm{O}$ infinito em ato faz com que as partes sejam partes intra partes, em que cada parte se prolonga ao tomar parte em novas relações com outras partes, constituindo dinamicamente um novo indivíduo, ainda mais complexo (ou amplo); o que, também, exige que cada pequena parte seja constituída também de partes intra partes ainda menores. Por um lado, não existe algo como um átomo ou uma unidade discreta mínima; por outro, tudo estaria, ao mesmo tempo, em uma relação que constitui sempre algo maior; lembremos como Espinosa define a própria noção do limite como isso que podemos conceber no interior de outro ainda maior e que o envolve; o que nos levaria ao limite de conceber a natureza como um único indivíduo, isso é a "fisionomia total do universo" como escreve Espinosa a Oldenburg (na carta 32). Contudo, Espinosa demonstra que ambos limites (tanto o atômico como a natureza como um único individuo) são entes abstratos sem realidade concreta na imanência da substância, ou melhor, são apenas auxila imaginari, auxiliares imaginários, ou entes de razão, de nossas operações intelectuais.
} 
recer e, assim, a harmonia universal perderia todo o seu privilégio de ordenação; e as dissonâncias à harmonia já não teriam de ser "resolvidas" e as divergências poderiam ser afirmadas em séries que escapariam à predeterminação, e, assim, dissolver-se-ia a própria harmonia preestabelecida. Segundo Deleuze:

dir-se-ia que a mônada, o cavaleiro de vários mundos, é mantida semiaberta como que por pinças. Uma vez que o mundo é agora constituído por séries divergentes (caosmos) ou que o lance de dados substitui o jogo do Pleno, a mônada já não pode incluir o mundo inteiro como um círculo fechado modificável por projeção, mas ela se abre a uma trajetória ou espiral em expansão, que se distancia cada vez mais de um centro. Já não se pode distinguir entre [...] o estado privado de uma mônada dominante (que produz em si mesma seus próprios acordos/acordes) e o estado público das mônadas em multidão (que seguem linhas de melodia), mas as duas entram em fusão numa espécie de diagonal em que as mônadas interpenetram-se, modificam-se, [...] constituindo outras tantas capturas transitórias. A questão é sempre habitar o mundo, mas o habitat musical [...] e o habitat plástico [...] não deixam subsistir a diferença entre o interior e o exterior, entre o privado e o público: eles identificam a variação da trajetória, e duplicam a monadologia com uma "nomadologia" (DELEUZE, 1991, p. 208).

Assim, as mônadas são desdobradas em uma atividade muito próxima à nossa concepção de imanência. Leibniz ficaria horrorizado, mas, a despeito de suas intenções, Deleuze está correto, pois para tornar a monadologia adequada ao que houve de mais radical na arte do XVII, esta teria que mudar a sua base mais elementar, a própria mônada, aproximandose ao que com maior intensidade procurou negar: a filosofia de Espinosa 7 .

Neste turbilhão imanente de

\footnotetext{
${ }^{7}$ Cabe lembrar que, em uma carta a Bourget, Leibniz afirma que, se não fossem as mônadas, sua filosofia cairia no espinosismo.
} 
uma arte que cada gesto, sem qualquer predeterminação, transborda a si mesmo, em um extremo imaginário onde o pintor se torna urbanista e vice-versa, eis que, neste limite da imanência "as esculturas são aí verdadeiros personagens, e a cidade é um cenário, sendo os próprios espectadores imagens pintadas ou esculturas. A arte inteira se torna socius, espaço social público, povoado de bailarinos barrocos" (DELEUZE, 1991, p. 187), como escrevera Deleuze. Nesta arte, em que a imagem de um desenho transborda-se na arquitetura, naturalmente acabamos por atingir a própria cidade em sua realidade sócio-histórica enquanto mais um limite desta "representação" poética. Neste sentido, temos uma arte que inclui o espectador real, em seu ato poético de transformação (criação), uma arte que não se contenta em ser a mera representação de um modelo de beleza abstrato, ideal ou transcendente, mas busca mesclar-se à própria realidade vivida na e pela própria cidade. Assim, muito distante da busca de um ideal externo que transcenda a própria realidade do artista, temos uma arte que não mais pode ser tomada enquanto mera representação ideal, mas é efeito da e procurará voltar-se para a própria realidade em que toma parte, na interioridade de um discurso e de uma ação histórica em pleno desenvolvimento. Assim, chegamos a uma arte que sequer representa a realidade, mas é parte de seu próprio discurso social, poético e histórico. Contudo, devemos nos lembrar que a multiplicidade destes artistas-atores, bailarinosespectadores (e demais variáveis atuantes) neste teatro vivo dançam uma música imanente, sem uma harmonia preestabelecida que lhes fornecesse uma continuidade linear e simples de suas tramas narrativas.

\section{II - Drama da imanência - Ben- jamin, Origem do drama barroco alemão, 1928}

O drama da imanência será figurado em uma das leituras filosóficas mais famosas e instigantes acerca do universo da arte seiscentista: a Origem do drama barroco alemão de Walter Benjamin, fazendo com que a multiplicidade sem predeterminação da imanência assuma um contorno completamente contrário ao espinosano, pois esta será tomada negativamente como um saldo de aleatoriedade e melancolia.

Pretendemos mostrar como as principais ideias presentes nos dois preâmbulos também estão, de certo modo, articuladas e desenhadas por Benjamin ao relacio- 
nar a imanência a mais uma forma de arte barroca: o teatro. No primeiro preâmbulo, vimos como Gebhardt concebe a imanência e a visualidade da pintura barroca enquanto formas não limitadas e portanto irracionais. No segundo preâmbulo, analisamos que para Deleuze a imanência e a música barroca são compreendidas como aberturas para uma multiplicidade de relações simultâneas que em ato negam qualquer predeterminação proveniente de uma harmonia metafísica transcendente. Nesta última parte, analisaremos como tais teses encontram-se entrelaçadas na imanência articulada entre irracionalidade e a negação de qualquer predeterminação transcendente que constituem a chave da compreensão do filósofo alemão acerca o luto que recobre a essência mais íntima do drama alemão seiscentista que encontrará no solo histórico sob o regime da imanência um dos principais motivos, se não o próprio, para o desacerto do mundo.

Benjamin conceberá a imanência como um poço de melancolia que, contrariamente à vitalidade da proposta por Espinosa, será figurada eminentemente na alegoria de um cadáver; assim, conduzimos nossa análise não exatamente para uma obra de arte, mas para o interior de uma das leituras mais melancólicas acerca do período barroco, onde vemos o drama da imanência, na expressão concebida Benjamin, se transformar em uma pilha de corpos. A consequência radical da assimilação da imanência à cena teatral alemã seria o efeito quase imediato da ação histórica de um mundo religiosamente incapaz de ascender ao plano transcendente, pois o mistério da crônica cristã, que abrangia a totalidade da história universal, não poderia mais ser encontrado quando, segundo Benjamin:

a cristandade europeia estava dividida numa multiplicidade de reinos cristãos, cujas ações históricas não mais aspiravam a transcorrer dentro do processo de salvação. O parentesco entre o drama barroco e o mistério é posto em questão pelo desespero radical que parecia ser a última palavra do drama cristão secularizado (BENJAMIN, 1984, p.101).

De fato, vários séculos de cristianismo que precederam o XVII tinham no mistério transcendente da Graça Divina a garantia do seu sentido último por uma história universal, ideal e revelada que nos 
conduziria em direção a nossa redenção; e, assim, todas as ações, das mais simples na vida cotidiana até as decisões mais contundentes e complicadas do Estado, teriam os seus papéis justificados, ainda que em um horizonte para além de uma história empírica e principalmente para além do entendimento humano. Segundo Benjamin, o drama alemão, ao contrário do barroco literário ibérico, teria se perdido inteiramente na desesperança da condição terrena; e mesmo a renascença, com seu intenso desenvolvimento humanista, em comparação à condição alemã, não apareceria como uma época incrédula de paganismo, mas como uma era profana e de grande liberdade mística e religiosa (BENJAMIN, 1984, p. 102).

Vemos então configurar-se no XVII alemão a origem do drama da imanência, expressão cunhada por Benjamin, como a imanência que em si mesma nunca poderia ser aceita como um bem, mas, sim, entendida como um castigo necessário enviado por Deus, devido ao mais antigo dos pecados, o original cometido por Adão. Nesta perspectiva, a imanência seria a condenação de uma vida longe de Deus: o personagem barroco, rebaixado à mera condição humana, seria completamente incapacitado da existência sacra, e mesmo o mundo que o cerca estaria aban- donado por Deus, constituindose como uma physis cega, a própria natureza em um estado de pura aleatoriedade. Eis que, mais baixo que os animais que habitariam um estado de ignorância inocente, restaria ao personagem barroco apenas o martírio da culpa de haver se perdido de Deus. O barroco teria se perdido das leis que ordenariam a vida mundana, essas completamente derivadas de uma causa transcendente, isto é, da vontade divina. Leis que, na interpretação de Benjamin, fariam com que a ação humana carecesse de qualquer poder efetivo e também de qualquer contingência, pois todas as ações seriam no máximo um produto secundário, seguindo a predeterminação da vontade divina, no máximo as suas ações teriam um papel acessório como no ocasionalismo de Malebranche. Esta causalidade transcendente, que fornecera o sentido comum a todos os seres humanos, seria irreparavelmente fraturada num século XVII reformado, em que o avanço da ideia de imanência irremediavelmente se propagaria com sua exigência de uma vida, em todos sentidos, terrena e profana.

A imanência nos forçaria a abandonar a imagem da ordem universal e predeterminada a partir de um aparato transcendente. Essa seria a velha imagem de or- 
dem transcendente que seria dilapidada em prol de uma nova ordem imanente, como nos demonstra a filosofia de Espinosa: por um lado, com esta, na ausência de qualquer transcendência, teríamos que abandonar a ideia de uma predeterminação em uma vontade divina, assim como a possibilidade de que a Terra se espelhasse em leis divinas, e, também, abandonar qualquer possível redenção escatológica extraterrena; além disto, a própria ciência que conceberia uma natureza hierarquizada dividida nas oposições reais de categorias e gêneros, herdadas de Aristóteles, que percorreriam toda a Idade Média, torna-se apenas um aparato imaginário, assim como os conceitos transcendentais como unidade, ser, verdade etc., capazes de identificar qualquer objeto ou realidade tomados apenas como entes de imaginação e, por fim, mas não por último em sua lista de efeitos heréticos, qualquer finalismo no seio da natureza deveria ontologicamente ser abandonado. Como resultado da imanência chegaríamos à anulação de qualquer teologia e mesmo teleologia. Assim, instala-se o mal verdadeiro neste mundo barroco reformado, pois julgando o sentido da imanência a partir dos enraizados parâmetros imaginários da antiga ordem transcendente, fazemos da imanência a imagem de algo absolutamente caótico, e sob tais termos o drama da imanência barroca é necessariamente compreendido como o efeito da catástrofe de uma natureza absolutamente aleatória e desprovida de sentido. E segundo Benjamin,

se e homem religioso do Barroco adere tanto ao mundo, é porque se sente arrastado com ele em direção a uma catarata. $\mathrm{O}$ barroco não conhece nenhuma escatologia; o que existe, por isso mesmo, é uma dinâmica que junta e exalta todas as coisas terrenas, antes que elas sejam entregues à consumação (BENJAMIN, 1984, p. 89).

Contudo, veremos que a grande catástrofe melancólica do drama da imanência não está na imanência, mas em um contraditório sentimento barroco que, por um lado, exclui a transcendência e, por outro, negativamente ainda a tem como um impossível horizonte desejado. Neste drama, a imanência contraditoriamente apenas existe em relação a aquilo que lhe é exterior, ou seja, esta se apresenta como negação da transcendência. Assim, a imanên- 
cia é dada exclusivamente pela perspectiva saudosista da transcendência perdida. Não por acaso, esta dramaturgia tem a imanência alegorizada no emblema do cadáver, e a base de sua trama ocorre sob o sentimento do luto: diríamos que seria o luto de haver perdido a própria sacralidade transcendente. Assim, a vida neste drama não excederia ao estado de luto da lembrança do corte com o divino, o que provocará o reinante sentimento de melancolia e a obsessão pelo cadáver que movem o drama alemão ${ }^{8}$. A própria noção da natureza imanente como uma physis cega e desgraçada, pois aleatória, só pode ser compreendida como a ideia de uma imanência incompleta, e constituída apenas como a carência da velha ordem predeterminada pela vontade ou por um ideal transcendentes?. Ou seja, a ordem imanente é tida por aleatória, pois a complexidade de sua ordem é a abertura para uma multiplicidade simultânea que se desdobra no novo e excede a perspectiva restrita e unívoca de uma linha teleológica, desde sempre e para sempre, predeterminada pela velha ordem transcendente. Por outro lado, para se encarar a imanência completa, ou seja, em sua plena positividade, seria preciso realmente abandonar a velha ordem transcendente, e não fazer como a contraditória maneira do drama barroco alemão que a nega somente para interiorizá-la disfarçada sob a forma de uma imanência incompleta e melancólica. Contudo, para a religiosidade, ainda que reformada, do barroco alemão, seria quase impossível aceitar um Deus realmente imanente que não fosse provido do atributo humano da livre escolha e da vontade para realizar uma ação; lembremos como Espinosa, na parte I da Ética, demonstra como, na imanência, a espontaneidade da ação divina, na verdade, segue de uma necessidade absoluta, nunca prérefletida, nem premeditada, nem decidida segundo uma escolha arbitrária; e esta será a perfeição de uma ação que decorre da necessidade intrínseca da identidade imanente entre essência e existência, entre natureza naturante e a natureza naturada.

\footnotetext{
${ }^{8}$ Lembremos que, em sua argumentação, Benjamin trabalha a gravura Melencolia I de Dürer como uma antecipação da amputação do espírito barroco expresso pelo drama da imanência.

9 Acompanhando Espinosa veremos justamente o contrário do que propõe o drama alemão, pois se levarmos a rigor a possibilidade do mundo ser criado e ordenado por uma causa voluntária que lhe seja externa, além de inúmeros problemas teológicos que restringem a própria perfeição de Deus, teríamos uma natureza desregrada e contingente, como demonstra Marilena Chaui, em 'Ontologia do necessário', quarto item do capítulo 6 do Nervura do Real (CHAUI, 1999, pp. 901-918).
} 
Lembremos que para Espinosa um dos momentos cruciais da vida ética é afastar a tristeza, sobretudo, a mais terrível de todas as tristezas, a melancolia e que, para ele, "não há nenhuma coisa em que o homem livre pense menos do que na morte, e sua sabedoria não é uma meditação sobre a morte, mas sobre a vida." (ESPINOSA, 2015, p. 483, Ética IV, P.67). Não poderia ser maior a distância em relação à concepção benjaminiana, na qual a imanência é transformada na obsessão com a morte, sequer tratandose da obsessiva reflexão sobre o fim da vida mundana e os seus desígnios futuros no eterno além túmulo (Inferno, Purgatório e Paraíso), mas como uma operação que consiste em encarar a vida em si mesma, em seu estado presente e terreno, já como a encarnação da morte. Neste sentido, o barroco de Benjamin, sempre contrário à filosofia de Espinosa, nunca será uma meditação sobre a vida, e "se os personagens do drama barroco morrem, [...] se eles são destruídos não é para que ascendam à imortalidade, mas que ascendam à condição de cadáver" (BENJAMIN, 1984, p.241). Assim, em oposição à vitalidade da concepção espinosana, o drama alemão, em sua imanência negativa, produziria inúmeras coisas que até então não tinham entrado em qualquer estruturação artística, como, por exemplo, as diversas práticas de martírios corporais enumeradas por Benjamin, nas quais fica explícito o prazer da crueldade do dramaturgo e das personagens (que se deliciam com o despedaçar da carne humana). Pois aos personagens de uma natureza desgraçada restaria da imanência somente o peso de seus corpos, cabendo-lhes apenas o ludismo sadomasoquista do martírio. Dentre os diversos exemplos citados por Benjamin, salta aos olhos a tentativa impossível de ascender a alguma significação sacra por meio da "dissecação anatômica em que as diversas partes do corpo são numeradas com uma insofismável alegria na crueldade desse ato" (BENJAMIN, 1984 , p.242). Pois se o corpo humano enquanto um organismo vivo (em sua opulência imanente) não cabe na estreiteza de um ícone simbólico que prometeria uma ascensão, as suas partes amputadas, classificadas e inertes talvez coubessem. Assim, a imagem do corpo humano despedaçado será mais uma das alegorias da "vida" barroca que, no mais primoroso e sádico dilaceramento, apenas produz a dispersão do corpo em uma inútil fragmentação classificatória em que inumeráveis cortes apenas reconduzem à falta de sentido, ao 
nada, ao vazio 10

\section{In Occafionem.}

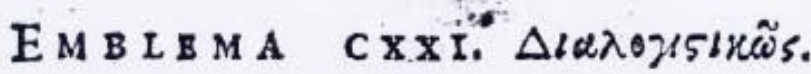

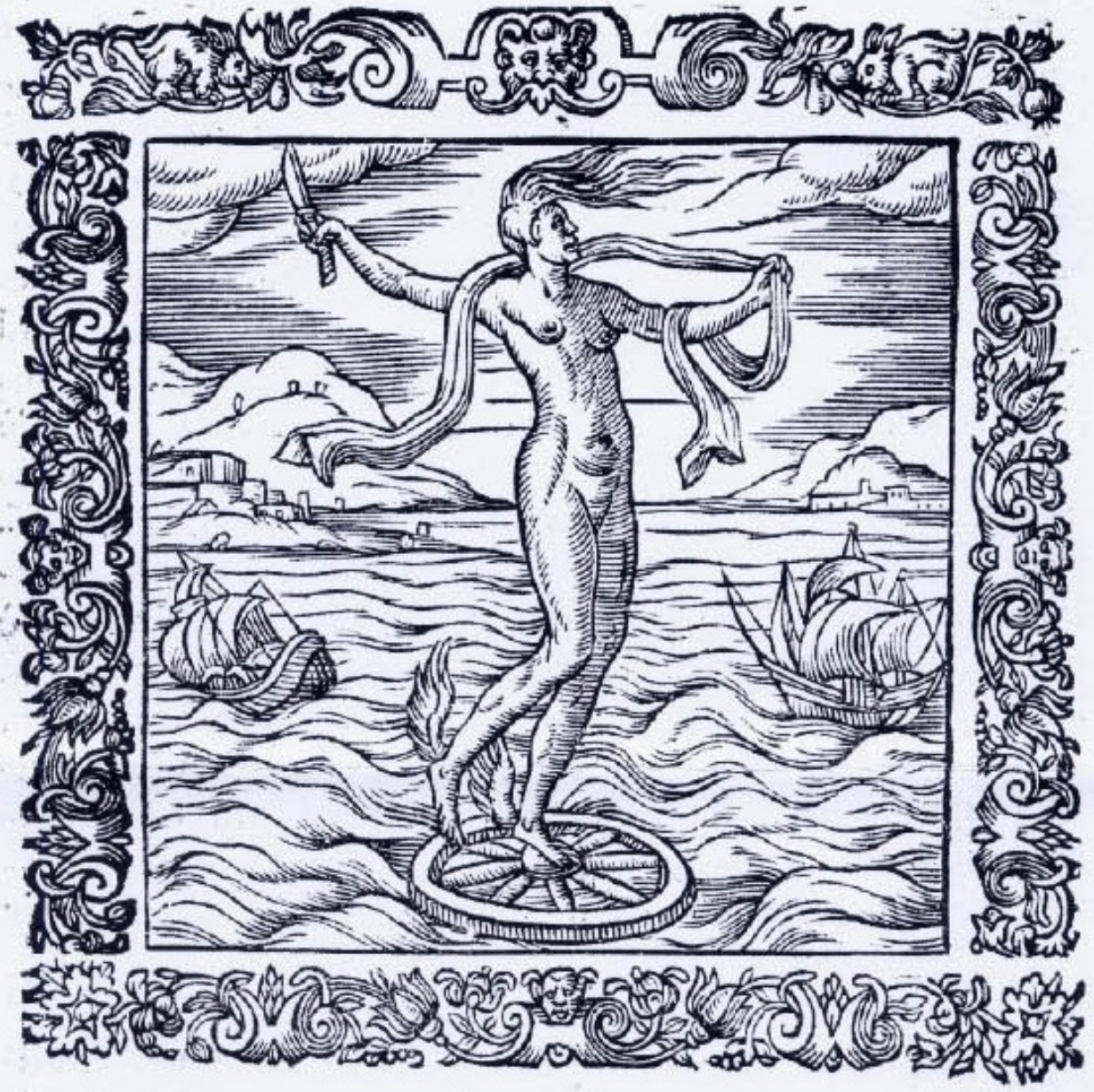

'In Occasionem’ emblema CXXI do livro Emblemata, de Andrea Alciato, edição de 1548.

\footnotetext{
${ }^{10}$ Mais ainda, para Benjamin o estado de exceção na política seria fruto desta imanência negativa que naturalmente levaria à contraditória soberania dos tiranos. Pois, uma vez que a realidade não possui uma ordem, ao soberano seria designada uma tarefa impossível: dar ordem a isso que essencialmente é necessariamente desprovido dela. Assim, restar-lhe-ia um contraditório e inexorável papel, também, de mártir, pois, sendo o soberano parte desta mesma natureza, as suas ações também seriam desprovidas de ordem e somente pela violência ele estabeleceria uma ordem social que, contudo, seria apenas a contingência melancólica redobrada. Por outro lado, em Espinosa, a democracia é o mais natural dos regimes, sendo explicado como um fruto da própria imanência. Assim, um desdobramento futuro a ser desenvolvido por nossa pesquisa tem como horizonte a compreensão da positividade da imanência na política. Gostaríamos de seguir as demonstrações de como uma ontologia imanente é a causa da estruturação da democracia real, entendida por Espinosa como o mais perfeito dos regimes políticos e assim dar uma resposta à equivocada aproximação entre imanência e estado de exceção.
} 
Vimos como a experiência humana, regulada pela imaginação ao buscar na natureza uma ordenação preestabelecida, linear e unívoca (como no drama de Benjamin), ao confrontar-se com a multiplicidade de uma ordenação imanente, parece nos condenar a viver em um labirinto de contingências de múltiplas causas simultâneas em múltiplos planos de acontecimentos que estão, ainda por cima, em constantes mutações ${ }^{11}$. Como se estivéssemos obrigados a viver à mercê da velha imagem feminina da fortund ${ }^{12}$, uma das alegorias mais famosas da literatura barroca, que no girar em falso de sua roda, de uma mesma maneira arbitrária, distribui e tira bens. Contudo, a Ética de Espinosa vem jogar luz e reforçar o contraste desta imagem desafortunada do labirinto de contingências, produzindo um claro contraste em que o próprio labirinto se desfaz ao expor, frente à multiplicidade do ente absolutamente infinito, um árduo e complexo, embora inequívoco, caminho rumo ao seu entendimento. A Ética, sua obra máxima, nos fornece um claro exemplo de como penetrar na ordem imanente desta multiplicidade em ato, que imaginariamente tanto inspira o medo de nossa fragilidade frente à fortuna. Penetrar neste caminho implica em entender a própria liberdade de uma natureza em um movimento constante de auto-diferenciação, ou seja, não se busca simplificála ou estagná-la, mas reconhecer a ordem desta transformação incessante que apenas imaginariamente pode ser tomada enquanto aleatoriedade. Entender, acima de tudo, seria um respeito ao que irredutivelmente é sempre complexo (e nunca poderia ser reduzida a uma perspectiva simples em uma linearidade predeterminada). Entender a sua complexidade é deslocar-se, movimentarse, expandir-se e no interior desta multiplicidade, é conscientemente ligar-se ao mundo, o que, ao mesmo tempo, significa agir racionalmente, pois é encontrar a potência da mente humana imersa no conhecimento da ordem fixa e imutável da natureza.

Neste caso, também não podemos cair no equívoco da má e superficial interpretação acerca do que seria "a ordem fixa e imutável da natureza" que nos leva-

\footnotetext{
${ }^{11}$ Como Espinosa escreve na Ética, no escólio da Proposição 42 da Parte V: “Com efeito, o ignorante, além de ser agitado pelas causas externas de muitas maneiras, e de nunca possuir o verdadeiro contentamento do ânimo, vive quase inconsciente de si, de Deus e das coisas;[...]" (ESPINOSA, 2015, p. 579.)

12 Como ilustrada no famoso emblema CXXI, 'In Occasionem', do livro Emblemata de Andrea Alciato cuja primeira publicação é de 1531 .
} 
ria a crer em um determinismo ou como se diz no XVII, um fatalismo - que impossibilitaria conceber a liberdade no interior da filosofia de Espinosa ${ }^{13}$; muito pelo contrario, quando nos voltamos, com o filósofo, para a ordem e co- nexão necessárias que definem a natureza imanente e que determinam a inteligibilidade de sua complexa atividade de transformação, vemos que nesta se radica a mais completa liberdade.

\section{Referências}

ALCIATO, A. (1548). Emblemata. PDF digital da edição de 1548, obtido na internet.

BENJAMIN, W. (1984). Origem do drama barraco alemão. São Paulo, Brasiliense.

CHAUI, M. (1999). 'Ontologia do necessário' quarto item do Cap. 6 do Nervura do Real, Vol. I, São Paulo, Companhia das Letras, pp. 901-918.

DELEUZE, G. (1991). A dobra, Leibniz e o barroco. Campinas, Papirus.

ESPINOSA, B. (2015). Ética. São Paulo, Edusp.

GEBHARDT, C. (2000). Spinoza, judaisme et barroque. Paris, Presses de l'Université Paris-Sorbone.

HEGEL, G. W. F. (1970). Leçons sur l'histoire de la philosophie. Paris, Gallimard.

WOLfFLIN, H. (2005). Renascença e Barroco. São Paulo, Perspectiva.

(1984). Conceitos fundamentais da História da Arte. São Paulo, Martins Fontes.

XAVIER, H. (2016). "Espinosa, melancolia e o absolutamente infinito na geometria dos indivisíveis do século XVII" . In: Cadernos Espinosanos, $\mathrm{n}^{\circ}$ 35, pp. 295-347.

Recebido: 02/07/2019

Aprovado: 09/11/2019

Publicado: $17 / 11 / 2019$

\footnotetext{
13 O equívoco imaginário de um fatalismo apenas ocorre quando supomos a ordem natural como linear e a liberdade como escolha voluntária em vista de fins.
} 
